\title{
Evaluating the Antimicrobial Potential of Eucalyptus baileyana F. Muell. and Eucalyptus major (Maiden) Blakely against the Fish Spoilage-causing Bacterium Shewanella putrefaciens
}

\author{
Mitchell Henry Wright ${ }^{1}$, Anthony Carlson Greene ${ }^{2}$, lan Edwin Cock ${ }^{2,3, *}$ \\ 'Leviathan Biosciences, Brisbane, Queensland, AUSTRALIA. \\ ${ }^{2}$ School of Environment and Science, Griffith University, Brisbane, Queensland, AUSTRALIA. \\ 'Environmental Futures Research Institute, Nathan Campus, Griffith University, Brisbane, Queensland, AUSTRALIA.
}

\begin{abstract}
Introduction: Eucalyptus baileyana (Bailey's stringy bark) and Eucalyptus major (Queensland grey gum) have been previously used as antimicrobials against a variety of ailments. This study evaluated the effectiveness of $E$. baileyana and E. major as inhibitory agents against Shewanella putrefaciens, a bacterium widely associated with fish spoilage. Methodology: $E$. baileyana and $E$. major extracts were prepared using the leaves of each plant with methanol or water as the extraction solvent. Growth inhibition and minimal inhibitory concentrations were determined against $S$. putrefaciens through disc diffusion assays. MIC values were subsequently quantified to evaluate the extracts efficacies as antibacterial agents. Finally, the toxicity of each extract was determined using the Artemia franciscana nauplii bioassay. Results: E. baileyana aqueous and methanolic leaf extracts inhibited the growth of $S$. putrefaciens in the disc diffusion assay, with MIC values of 1411 and $1221 \mu \mathrm{g} / \mathrm{mL}$ respectively. Similarly, $E$. major leaf extracts also showed growth inhibition of $S$. putrefaciens, with MIC values of $1686 \mu \mathrm{g} / \mathrm{mL}$ for the aqueous extract, and $1160 \mu \mathrm{g} / \mathrm{mL}$ for the methanolic extract. However, toxicity studies of the extracts revealed that all extracts were toxic and likely unsuitable for human consumption $\left(\mathrm{LC}_{50}\right.$ values $455-1146 \mu \mathrm{g} / \mathrm{mL}$ ) as determined by the Artemia franciscana
\end{abstract}

bioassay. Conclusion: While the E. baileyana and E. major leaf extracts were effective in preventing microbial growth, given their relatively high levels of toxicity, they would not be suitable for use as a preservative in the prevention of fish spoilage. However, the antibacterial capacity of the extracts indicates that the extracts may show promise as a surface disinfectant, and this should be investigated further.

Key words: Fish spoilage, Shewanella putrefaciens, Eucalyptus major, Eucalyptus baileyana, Eucalypts, Medicinal plants.

\section{Correspondence:}

Dr. Ian Edwin Cock

${ }^{2}$ School of Environment and Science, Griffith University, Brisbane, Queensland, AUSTRALIA.

${ }^{3}$ Environmental Futures Research Institute, Nathan Campus, Griffith University, Brisbane, Queensland, AUSTRALIA

Phone no: +61 737357637

E-mail: i.cock@griffith.edu.au

DOI: $10.5530 /$ pc.2021.2.24

\section{INTRODUCTION}

Food spoilage is the deterioration of food that results in it becoming undesirable or unfit for consumption. This can be chemical spoilage (oxidation, chemical/metal contamination) or biological spoilage (insects, microbial growth), resulting in adverse changes to taste, texture, appearance and/or smell. ${ }^{1}$ Microbial spoilage arises through the contamination of foods by acids and other wastes, which are typically biproducts produced as a result of metabolic processes. ${ }^{2}$ While most major organisms associated with food contamination are nonpathogenic, these processes often render the food inedible and microbes are estimated to contribute to $25 \%$ of all spoilage. ${ }^{3}$ As such, food producers employ numerous strategies to mitigate spoilage, including, but not limited to, the addition of preservatives. These are typically chemical compounds that are well-documented as antimicrobial agents. However, these preservatives are often viewed by the general public in a negative light, despite often being well-documented as safe for human ingestion. ${ }^{3}$ For industries concerned about consumer perception, natural products (plants containing antimicrobial agents) can be substituted as a more favourable alternative. ${ }^{4}$ The suitability of employing natural products to mitigate spoilage caused by microbial growth depends on several factors:

Antimicrobial capacity: For any intervention to be successful, the plant being used must contain antimicrobials that effectively inhibit microbial growth.

Toxicity: The plant cannot be poisonous to the humans/animals that will ingest the food product.
Secondary spoilage: The plant cannot cause secondary spoilage. This can occur either through chemical reactions between the product and the food, or through undesirable tastes/aromas associated with the plant itself.

Undertaking an all-encompassing study on the effectiveness of a plant in preventing food spoilage is a massive endeavour. This paper focuses on one of the prevailing bacteria associated with fish spoilage, Shewanella putrefaciens, and its susceptibility to the native Australian plants, Eucalyptus major and Eucalyptus baileyana, as well toxicity studies to evaluate their suitability for inclusion into food products.

Plants from the genus Eucalyptus, including E. major and E. baileyana, are widely documented for their antiseptic properties. Historically, E. major and E. baileyana have been used to remedy throat infections, achieved through the crushing of the leaves and subsequent inhalation of released volatiles. ${ }^{5}$ Furthermore, preparation of oils/infusions from these leaves produce effective topical antiseptics. These concoctions, when applied to skin diseases or wounds, offer protection against infection. ${ }^{6}$ Studies investigating the antibacterial properties of E. major and E. baileyana extracts have shown strong levels of inhibition against a variety of pathogenic bacteria, including Bacillus anthracis, the causative agent of anthrax. ${ }^{7}$ Eucalyptus-derived essential oils remain incredibly popular today worldwide, serving as a natural alternative to the treatment of many common ailments. 


\section{MATERIALS AND METHODS}

\section{Plant source and extraction}

Eucalyptus baileyana and Eucalyptus major leaf materials were collected from Toohey Forest, Brisbane and were identified with reference to a taxonomic key to Toohey Forest plants. ${ }^{8}$ The leaf materials were dried thoroughly using a Sunbeam Food Dehydrator and stored at $-30^{\circ} \mathrm{C}$ until used. Prior to use, the leaf materials were thawed and ground into a coarse powder. Individual $1 \mathrm{~g}$ quantities were weighed into separate tubes and $50 \mathrm{~mL}$ of either methanol or water added, followed by a $24-\mathrm{hr}$ incubation period at $4^{\circ} \mathrm{C}$ with gentle shaking. Finally, the extracts were filtered using Whatman No. 54 filter paper under vacuum, followed by drying by rotary evaporation in an Eppendorf Concentrator 5301. The resultant dry extract was weighed and redissolved in $10 \mathrm{~mL}$ deionised water (containing $1 \%$ DMSO).

\section{Qualitative phytochemical studies}

Phytochemical analysis of the extracts for the presence of flavonoids, triterpenoids, cardiac glycosides, polysteroids, saponins, phenolic compounds, anthraquinones, tannins and alkaloids were conducted by previously described assays. ${ }^{9,10}$

\section{Environmental Shewanella putrefaciens strain}

Shewanella putrefaciens strain CN-32 was obtained from Professor Kenneth Nealson of the University of Southern California (USA). Antibacterial screening was achieved using a modified peptone/yeast extract (PYE) agar as previously described, ${ }^{11}$ containing: $1 \mathrm{~g} / \mathrm{L}$ peptone, $1.5 \mathrm{~g} / \mathrm{L}$ yeast extract, $7.5 \mathrm{~g} / \mathrm{L} \mathrm{NaCl}, 1 \mathrm{~g} / \mathrm{L}$ ammonium persulfate, $2.4 \mathrm{~g} / \mathrm{L}$ HEPES buffer ( $\mathrm{pH} 7.5)$ and $16 \mathrm{~g} / \mathrm{L}$ bacteriological agar. Incubation was at $30^{\circ} \mathrm{C}$ and the stock culture was subcultured and maintained in PYE media at $4^{\circ} \mathrm{C}$. The media nutrient components were supplied by Oxoid Ltd. The GenBank accession number for the complete genome for $S$. putrefaciens CN-32 is CP000681.

\section{Evaluation of antimicrobial activity}

Antimicrobial activity was determined using a modified disc diffusion assay as previously described. ${ }^{6,12}$ Briefly, $100 \mu \mathrm{L}$ of $S$. putrefaciens was grown in $10 \mathrm{~mL}$ of PYE media until they reached a count of $\sim 10^{8}$ cells/ $\mathrm{mL}$. An amount of $100 \mu \mathrm{L}$ of bacterial suspension was evenly spread onto PYE agar plates. The extracts were assessed for antibacterial activity using $6 \mathrm{~mm}$ sterilised filter paper discs. Discs were treated with $10 \mu \mathrm{L}$ of an extract, allowed to dry before being placed onto inoculated plates. The plates were set at $4^{\circ} \mathrm{C}$ for $2 \mathrm{~h}$ before incubation at $30^{\circ} \mathrm{C}$ for $24 \mathrm{~h}$ and the inhibition zone diameters measured in millimetres. All measurements were rounded to the closest whole millimetre and performed in triplicate. Mean values $( \pm$ SEM) are reported in this study. Standard discs of chloramphenicol $(10 \mu \mathrm{g})$ were obtained from Oxoid Ltd. and served as a positive control. Filter discs treated with $10 \mu \mathrm{L}$ of sterilised deionised water were used as a negative control.

\section{Minimum inhibitory concentration (MIC) determination}

The minimum inhibitory concentration (MIC) of the extracts was determined as previously described. ${ }^{13,14}$ Briefly, each extract was diluted in deionised water and tested across a range of concentrations. Discs were treated with $10 \mu \mathrm{L}$ of the test dilutions, allowed to dry and placed onto inoculated plates. The assay was performed as outlined above, and graphs plotting the zones of inhibition versus concentration were visualised. Linear regression was used to determine the MIC values.

\section{Toxicity screening}

\section{Reference toxin for toxicity screening}

Potassium dichromate $\left(\mathrm{K}_{2} \mathrm{Cr}_{2} \mathrm{O}_{7}\right)$ (AR grade, Chem-Supply, Australia) was prepared as a $4 \mathrm{mg} / \mathrm{mL}$ solution in sterilised deionised water, and serially diluted in artificial seawater for use in the Artemia franciscana nauplii bioassay as previously described. ${ }^{15}$

\section{Artemia franciscana nauplii toxicity screening}

Toxicity was tested using a modified Artemia franciscana nauplii lethality assay as previously described. ${ }^{15,16}$ Briefly, $400 \mu \mathrm{L}$ of seawater containing approximately 43 (mean 43.2, $n=155$, SD 14.5) nauplii were added to a 48 well plate and immediately used for bioassaying. Volumes of $400 \mu \mathrm{L}$ of diluted extracts, or the reference toxin, were transferred to the wells and incubated at $25 \pm 1{ }^{\circ} \mathrm{C}$ under artificial light (1000 Lux). A negative control $(400 \mu \mathrm{L}$ seawater) was run in triplicate for each plate and all treatments were performed in triplicate. The wells were checked at regular intervals and the dead nauplii tabulated. The nauplii were considered dead if no movement of the appendages were detected within $12 \mathrm{sec}$. After $24 \mathrm{hr}$ all nauplii were sacrificed and counted to determine the total \% mortality per well. The $\mathrm{LC}_{50}$ with $95 \%$ confidence limits for each treatment was determined using ProBit analysis.

\section{Statistical analysis}

Data is presented as the mean \pm SEM of at least three independent experiments.

\section{RESULTS}

\section{Liquid extraction yields and qualitative phytochemical screening}

Extraction of $1 \mathrm{~g}$ of the E. baileyana and E. major leaf plant materials with the solvents yielded dried plant extracts ranging from $125 \mathrm{mg}(E$. baileyana aqueous extract) to $280 \mathrm{mg}$ (E. major methanolic extract) (Table 1). The methanolic extracts generally gave higher yields of dried extracted material compared with the corresponding aqueous extracts in both eucalypts, although this difference was much less significant with E. baileyana. The dried extracts were resuspended in $10 \mathrm{~mL}$ of sterile deionised water (containing $1 \%$ DMSO) and resulted in the extract concentrations shown in Table 2.

\section{Antimicrobial activity}

To assess the ability of the leaf extracts to inhibit $S$. putrefaciens growth, aliquots $(10 \mu \mathrm{L})$ of each extract were screened using disc diffusion assaying as previously described. ${ }^{17,18}$ Bacterial growth was inhibited by

Table 1: Minimum inhibitory concentration $(\mu \mathrm{g} / \mathrm{mL})$ of the leaf extracts and $\mathrm{LC}_{50}$ values $(\mu \mathrm{g} / \mathrm{mL})$ in the Artemia nauplii bioassay.

\begin{tabular}{ccc}
\hline Species & Extract & MIC $(\mu \mathrm{g} / \mathrm{mL})$ \\
\hline E. baileyana & $\mathrm{W}$ & 1411 \\
E. baileyana & $\mathrm{M}$ & 1221 \\
E. major & $\mathrm{W}$ & 1686 \\
E. major & $\mathrm{M}$ & 1160 \\
Potassium Dichromate & & \\
\hline
\end{tabular}

$\mathrm{W}=$ aqueous; $\mathrm{M}=$ methanolic. Numbers indicate the mean MIC and $\mathrm{LC}_{50}$ values of triplicate determinations. - indicates no bacterial growth inhibition was evident, or that an $\mathrm{LC}_{50}$ value could not be obtained as the mortality did not reach $50 \%$ for any dose tested. 
Table 2: The mass of dried leaf material, the concentration after resuspension in deionised water, qualitative phytochemical screenings of the plant extracts.

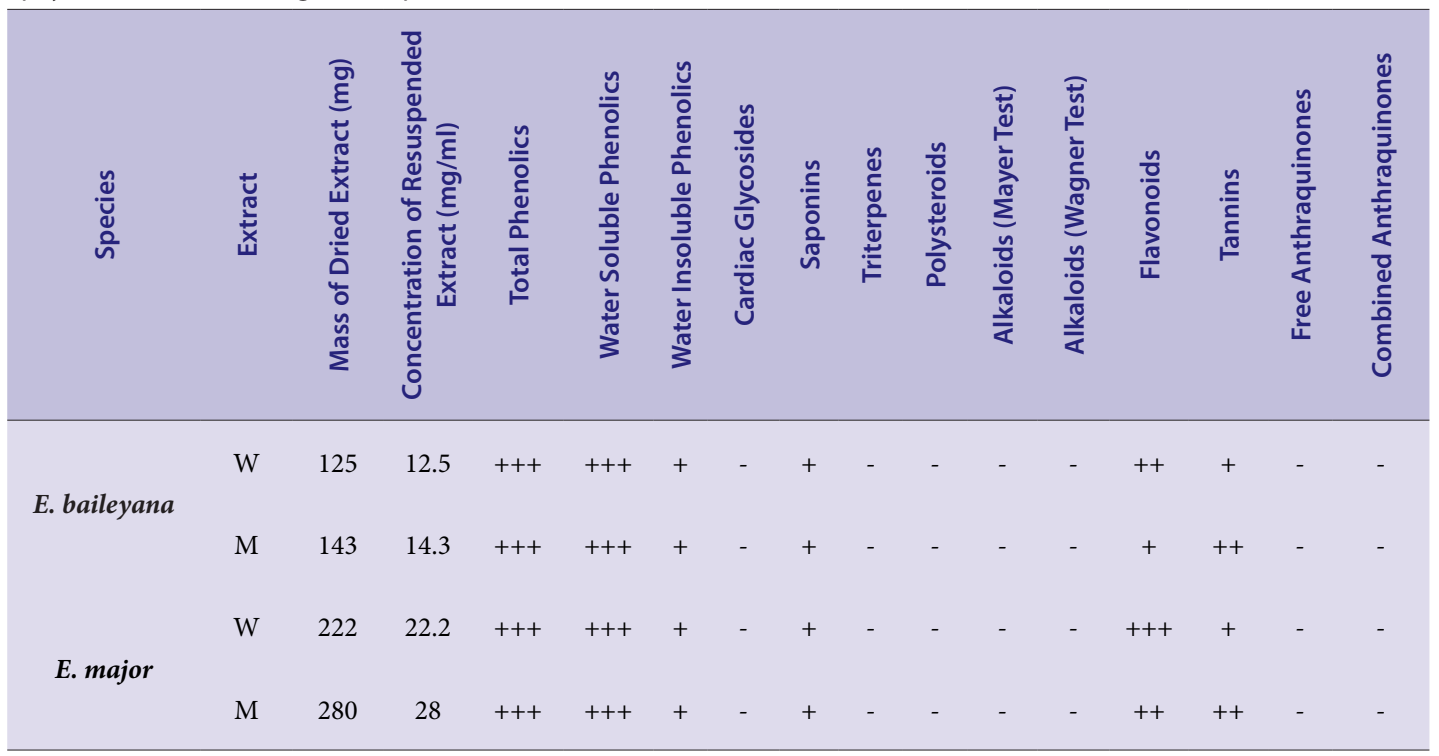

$\mathrm{W}=$ aqueous; $\mathrm{M}=$ methanolic. +++ indicates a large response; ++ indicates a moderate response; + indicates a minor response; - indicates no response detected.

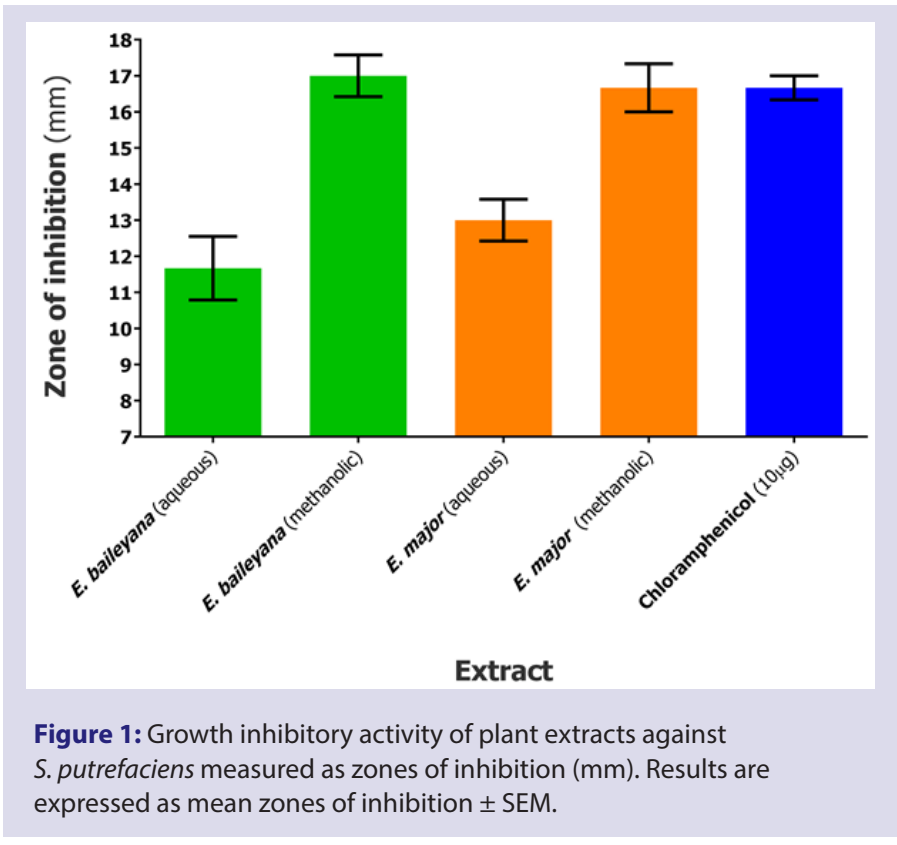

all the extracts tested (Figure 1). Comparatively, the methanolic leaf extracts were more potent inhibitors of growth (as judged by zone of inhibition) compared to their aqueous counterparts, with inhibition zones of $17 \pm 0.6 \mathrm{~mm}$ and $16.7 \pm 1.0 \mathrm{~mm}$ respectively. These results compare favourably with those of the chloramphenicol control, which provided inhibitory zones of $16.7 \pm 0.3 \mathrm{~mm}(10 \mu \mathrm{g})$.

The antimicrobial efficacy was further quantified by determining the MIC values (Table 2). The methanolic E. baileyana and E. major methanolic extracts were particularly effective at inhibiting microbial growth, with MIC values against S. putrefaciens $<1221 \mu \mathrm{g} / \mathrm{mL}$ (E. baileyana) and $<1160 \mu \mathrm{g} / \mathrm{mL}$ (E. major) ( $12 \mu \mathrm{g}$ impregnated in the disc). Similarly, the aqueous extracts also provided strong levels of inhibition, yielding MICs

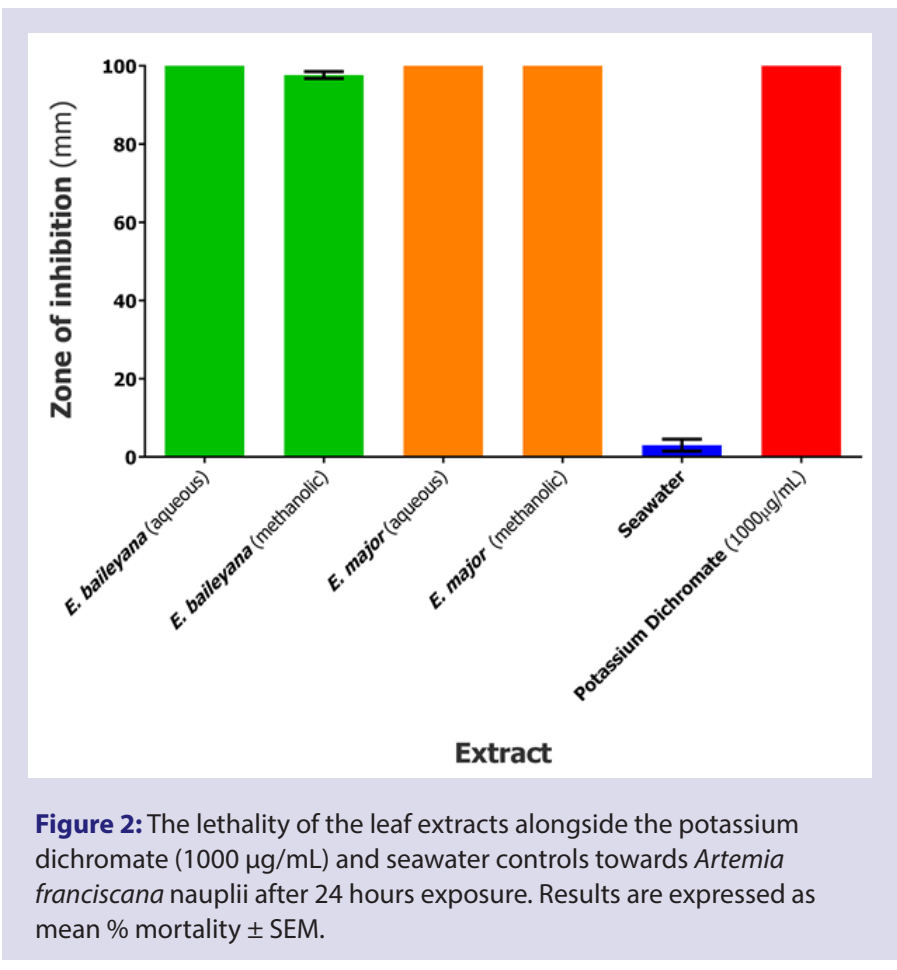

of putrefaciens $<1411 \mu \mathrm{g} / \mathrm{mL}$ (E. baileyana) and $<1686 \mu \mathrm{g} / \mathrm{mL}$ (E. major).

\section{Quantification of toxicity}

All extracts were initially screened at $2000 \mu \mathrm{g} / \mathrm{mL}$ in the assay (Figure 2). Potassium dichromate $(1000 \mu \mathrm{g} / \mathrm{mL})$ was used as a reference toxin, and seawater used as a negative control. The potassium dichromate screening showed onset of mortality, inducing nauplii death within the first $3 \mathrm{hr}$ of exposure and $100 \%$ mortality after 4-5 hr (results omitted). All the leaf extracts tested displayed $>95 \%$ mortality rates at $24 \mathrm{~h}$. 
To further quantify the effect of toxin concentration on mortality, the leaf extracts were serially diluted in artificial seawater to test across a range of concentrations in the Artemia nauplii bioassay. To further quantify the effect of toxin concentration on mortality, the leaf extracts were serially diluted in artificial seawater to test across a range of concentrations in the Artemia nauplii bioassay. Table 1 shows the $\mathrm{LC}_{50}$ values each extract towards $A$. franciscana. Significant toxicity was noted for both E. baileyana extracts as well as the E. major leaf methanolic extract with $\mathrm{LC}_{50}$ values substantially $<1000 \mu \mathrm{g} / \mathrm{mL}$, indicating that they are toxic. Similarly, the E. major leaf aqueous extract returned an $\mathrm{LC}_{50}$ of $1146 \mu \mathrm{g} /$ $\mathrm{mL}$, indicating that it was nontoxic. The relative toxicity of each extract using the $\mathrm{LC}_{50}$ values obtained was achieved as previously described. ${ }^{15,16}$

\section{DISCUSSION}

Previous studies have highlighted the ability for E. major and E. baileyana to inhibit pathogenic bacterial species, ${ }^{5}$ although this study is the first to investigate their potential in the prevention of food spoilage. From an antimicrobial standpoint, both the aqueous and methanolic E. major and E. baileyana leaf extracts were effective in preventing S. putrefaciens growth. Unfortunately, subsequent toxicity studies revealed that these extracts are unsuitable for human consumption and thus cannot be used as preservatives. However, these results are still promising in that during the preparation for the market, fish are generally gutted and sliced into smaller pieces, so they are ready for purchase by the customer. During this process, surface contamination by bacteria is inevitable and Eucalypt leaf extracts may offer a natural alternative as a cleaning agent for these environments. Still, determining the suitability of E. major and E. baileyana extracts would require additional testing and was not within the scope of this study.

Studies using extracts from other plants have also reported potent MIC values signifying potent Shewanella spp. growth inhibitory activity. One recent study reported an MIC value of $512 \mu \mathrm{g} / \mathrm{mL}$ against a different environmental S. putrefaciens isolate by an ethanolic Zataria multiflora extract. ${ }^{19}$ Zataria multiflora is commonly used in the Middle East as both a natural food preservative, and as a medicinal plant. Based on its antiseptic properties, it is considered to have potent growth inhibitory properties against a wide variety of pathogenic and non-pathogenic bacteria. ${ }^{19}$ A different study reported moderate growth inhibition $(2 \mathrm{mg} /$ $\mathrm{mL}$ ) of $S$. putrefaciens by aqueous Terminalia catappa extracts. ${ }^{20}$ That plant is widely regarded for its antibacterial properties and is believed to have potent broad spectrum antibacterial activity. ${ }^{21}$ More recently, we reported potent inhibitory activity of Terminalia ferdinandiana Exell extracts against four Shewanella spp. ${ }^{4}$

Although phytochemical analyses were outside the scope of our investigation, previous literature has highlighted that the members of genus Eucalyptus are widely associated with their high terpenoid content. ${ }^{22,23}$ Of note, numerous Eucalyptus spp. have been reported to contain high levels of 1,8-cineol, a terpenoid well-documented as an antibacterial agent ${ }^{24,25}$ and it is likely that this compound contributes to the activity reported herein. This compound has also been reported to be toxic ${ }^{26,27}$ and may account for the toxicity reported in our study. Whilst this toxicity would impact on the usefulness of these extracts as natural fish preservatives, that would not preclude its use as topical medicinal agents and further work is required to explore other uses of these extracts.

\section{CONCLUSION}

The results of this study demonstrate that despite the noteworthy $S$. putrafaciens inhibitory activity of E. major and E. baileyana their toxicity would limit their potential as natural fish/seafood preservatives.

\section{ACKNOWLEDGEMENT}

The authors are most grateful to Professor Kenneth Nealson of the University of Southern California, USA for the gift of all environmental Shewanella spp. strain, used in this study. Financial support for this work was provided by the Environmental Futures Research Institute and the School of Environment and Science, Griffith University, Australia.

\section{CONFLICT OF INTEREST}

The authors report no conflicts of interest.

\section{ABBREVIATIONS}

DMSO: Dimethyl sulfoxide; $\mathbf{L C}_{50}$ : The concentration required to achieve $50 \%$ mortality; MIC: minimum inhibitory concentration; ZOI: zone of inhibition.

\section{REFERENCES}

1. Huis VJHJ. Microbial and biochemical spoilage of foods: An overview. International Journal of Food Microbiology. 1996;33(1):1-18.

2. Wright $M H$, Matthews B, Arnold MS, Greene AC, Cock IE. The prevention of fish spoilage by high antioxidant Australian culinary plants: Shewanella putrefaciens growth inhibition. International Journal of Food Science and Technology. 2016;51(3):801-13

3. Ghaly AE, Dave D, Budge S, Brooks MS. Fish Spoilage Mechanisms and Preservation Techniques: Review. American Journal of Applied Sciences. 2010;7(7):859-77.

4. Wright MH, Shalom J, Matthews B, Greene AC, Cock IE. Terminalia ferdinandiana Exell: Extracts inhibit Shewanella spp. growth and prevent fish spoilage. Food Microbiology. 2019;78:114-22.

5. Wright $\mathrm{MH}$, Greene AC, Cock IE. Inhibition of Bacillus anthracis growth by Australian native plants used traditionally as antibacterial medicines. Pharmacogn J. 2015;7(6):389-96. doi:10.5530/pj.2015.6.13

6. Cock IE, Vuuren SFV. South African food and medicinal plant extracts as potential antimicrobial food agents. Journal of Food Science and Technology. 2015;52(11):6879-99.

7. Lee CJ, Wright MH, Greene AC, et al. Preliminary Evaluations of the Antibacterial Activity of Tasmannia lanceolata against Bacillus anthracis: Natural Resource Probing to Prevent Anthrax. Pharmcog Commn. 2019;9(4):124-9. doi:10.5530/ pc.2019.4.26

8. Coutts RH, Catterall CP. Identifying the plants of Toohey Forest, Ecos Educational Publishers; Nambour, Australia. 1980.

9. Shalom J, Cock IE. Terminalia ferdinandiana Exell. fruit and leaf extracts inhibit proliferation and induce apoptosis in selected human cancer cell lines. Nutrition and Cancer. 2018;70(4):579-93.

10. Ilanko A, Cock IE. The interactive antimicrobial activity of conventional antibiotics and Petalostigma spp. extracts against bacterial triggers of some autoimmune inflammatory diseases. Pharmacognosy Journal. 2019;11(2).

11. Murhekar S, Wright MH, Greene AC, Brownlie JC, Cock IE. Inhibition of Shewanella spp. growth by Syzygium australe and Syzygium luehmanni extracts: Natural methods for the prevention of fish spoilage. Journal of Food Science and Technology. 2017;54(10):3314-26.

12. Sirdaarta J, Matthews B, Cock IE. Kakadu plum fruit extracts inhibit growth of the bacterial triggers of rheumatoid arthritis: Identification of stilbene and tannin components. Journal of Functional Foods. 2015;17:610-20.

13. Cheesman MJ, White A, Matthews B, Cock IE. Terminalia ferdinandiana fruit and leaf extracts inhibit methicillin-resistant Staphylococcus aureus growth. Planta Medica. 2019;85(16):1253-62.

14. Tiwana G, Cock IE, White A, Cheesman MJ. Use of specific combinations of the triphala plant component extracts to potentiate the inhibition of gastrointestinal bacterial growth. Journal of Ethnopharmacology. 2020;260:112937.

15. Cock IE, Ruebhart DR. Comparison of the brine shrimp nauplii bioassay and the ToxScreen-II test for the detection of toxicity associated with Aloe vera (Aloe barbadensis Miller) leaf extract. Pharmacognosy Research. 2009;1(2):98-101.

16. Lee CJ, Wright MH, Arnold MS, Greene AC, Cock IE. Inhibition of Streptococcus pyogenes growth by native Australian plants: New approaches towards the management of impetigo, pharyngitis and rheumatic heart disease. Pharmacognosy Communications. 2016;6(3):164.

17. McManus $\mathrm{K}$, Wood A, Wright $\mathrm{MH}$, et al. Terminalia ferdinandiana Exell. Extracts inhibit the growth of body odour-forming bacteria. Int J Cosmet Sci. 2017;39(5):500-10. doi:10.1111/ics.12403

18. Wright $\mathrm{MH}$, Lee CJ, Pollock $\mathrm{CE}$, et al. Growth Inhibitory Activity of Selected High Antioxidant Australian Syzygium Species against the Food Poisoning and Tissue Necrotic Pathogen Clostridium Perfringens. Pharmacogn Commn. 
2016;6(2):93-9. doi:10.5530/pc.2016.2.7

19. Motevasel M, Zomorodian K, Ashraf MMA, et al. The anti-bacterial effects of Zataria multiflora extract on common pathogenic Gram positive cocci, pathogenic Gram negative bacilli and non-pathogenic bacteria. African Journal of Microbiology Research. 2011;5(28):4993-6.

20. Chansue N, Assawawongkasem N. The in vitro antibacterial activity and ornamental fish toxicity of the water extract of Indian almond leaves (Terminalia catappa Linn.). Veterinary Research Article. 2008;18(1):36-45.

21. Cock IE. The medicinal properties and phytochemistry of plants of the genus Terminalia (Combretaceae). Inflammopharmacology 2015;23(5):203-29. DOI: 10.1007/s10787-015-0246-z

22. Sørensen M, Rinnan R, Woodrow l, et al. The entangled dynamics of eucalypt leaf and flower volatile emissions. Environmental and Experimental Botany. 2020;176:104032.

23. Barton AF, Tjandra J, Nicholas PG. Chemical evaluation of volatile oils in Eucalyptus species. Journal of Agricultural and Food Chemistry. 1989;37(5):1253-7.

24. Sefidkon F, Assareh $M H$, Abravesh $Z$, et al. Chemical composition of the essential oils of four cultivated Eucalyptus species in Iran as medicinal plants (E. microtheca, E. spathulata, E. largiflorens and E. torquata). Iranian Journal of Pharmaceutical Research. 2010;20(2):135-40.

25. Ieri F, Cecchi L, Giannini E, et al. GC-MS and HS-SPME-GC $\times$ GC-TOFMS determination of the volatile composition of essential oils and hydrosols (byproducts) from four Eucalyptus species cultivated in Tuscany. Molecules. 2019;24(2):226

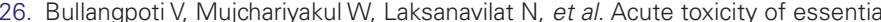
oil compounds (thymol and 1,8-cineole) to insectivorous guppy, Poecilia reticulata Peters, 1859. Agriculture and Natural Resources. 2018;52(2):190-4

27. Scalerandi E, Flores GA, Palacio $M$, et al. Understanding synergistic toxicity of terpenes as insecticides: Contribution of metabolic detoxification in Musca domestica. Frontiers in Plant Science. 2018;9:1579.

\section{PICTORIAL ABSTRACT}

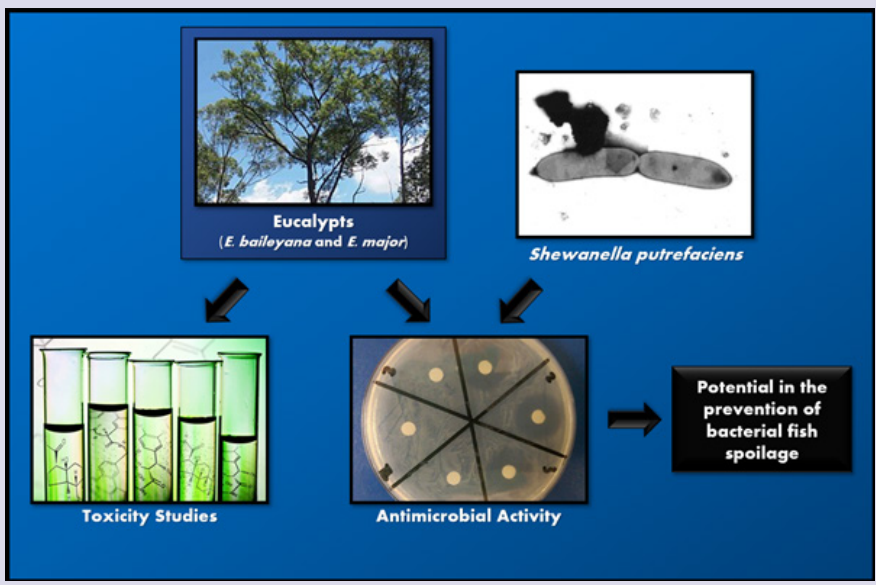

\section{SUMMARY}

- Eucalyptus baileyana and Eucalyptus major extracts were tested for the ability to inhibit the growth of fish spoilage bacteria.

- The extracts were also tested for toxicity in the Artemia nauplii bioassay.

- All extracts were good inhibitors of Shewanella putrefaciens growth but displayed substantial toxicity.

- $\quad$ The usefulness of the Eucalyptus extracts as a fish preservative would be limited by their toxicity.
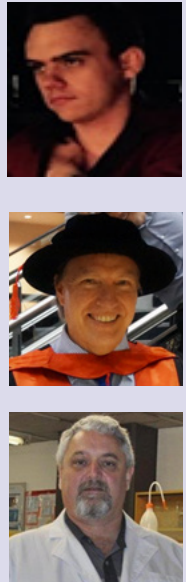

\section{ABOUT AUTHORS}

Dr. Mitchell Henry Wright is a Geomicrobiologist who received his Ph.D. in 2014 for his work investigating the manganese reduction/ oxidation characteristics of environmental bacteria. From 2016 to 2018 he undertook a postdoctoral researcher role under the mentorship of Prof. Bradley Tebo, where he explored the bacterial oxidative formation and removal of complexed Mn(III) and the implications of these processes on the global ocean. Upon returning to Australia, Dr. Mitchell H. Wright was recruited by First Choice College and to date, oversees their Department of Research and Development. Additionally, he has returned to his former lab (lead by Dr. lan Cock) to continue his research into the antimicrobial potential of native plants.

Dr. Anthony Carlson Greene is a senior lecturer and researcher at Griffith University, Brisbane Australia. He obtained his PhD in Microbiology from the University of New South Wales and focuses on extreme environments, bioremediation and geomicrobiology. His specific interests include the microbial ecology of thermophilic, saline and alkaliphilic environments and the mechanisms and industrial potential of extremophilic bacteria contained therein.

Dr. Ian Cock leads a research team in the Environmental Futures Research Institute and the School of Natural Sciences at Griffith University, Australia. His research involves bioactivity and phytochemical studies into a variety of plant species of both Australian and international origin, including Aloe vera, South Asian and South American tropical fruits, as well as Australia plants including Scaevola spinescens, Pittosporum phylliraeoides, Terminalia ferdinandiana (Kakadu plum), Australian Acacias, Syzygiums, Petalostigmas and Xanthorrhoea johnsonii (grass trees). This range of projects has resulted in over 150 publications across a variety of peer reviewed journals. 